\title{
Cardiometabolic markers among Argentinean normal weight and overweight children with and without central obesity
}

\author{
Valeria Hirschler ${ }^{1}$, Claudia Molinari ${ }^{1}$, Silvia Lapertosa ${ }^{2}$, Gustavo Maccallini ${ }^{3}$ and Claudio D Gonzalez ${ }^{4}$ \\ 'University of Buenos Aires, Buenos Aires, Argentina \\ ${ }^{2} \mathrm{UNNE}$, Corrientes, Argentina \\ ${ }^{3}$ Hidalgo Laboratories, Buenos Aires, Argentina \\ ${ }^{4}$ CEMIC, Buenos Aires, Argentina
}

Correspondence should be addressed to V Hirschler: vhirschler@gmail.com

\begin{abstract}
Background: The association between central obesity and cardiometabolic complications justifies exploring its association in normal-weight and overweight/obese (OW/OB) schoolchildren.

Objective: To describe cardiometabolic markers in four groups according to BMI/WC categories: (i) normal weight with central OB; (ii) normal weight without central OB; (iii) OW/OB with central OB and (iv) OW/OB without central OB, in a sample of Argentinean schoolchildren.

Methods: A cross-sectional study of 1264 Argentinean schoolchildren (624 F), aged $9.5 \pm 2.2$ years was performed between November 2013 and 2015. Children's anthropometric measures, blood pressure (BP), glucose, lipids, and insulin were measured. Children were divided into four groups: (i) normal weight with central OB; (ii) normal weight without central OB; (iii) OW/OB with central OB and (iv) OW/OB without central OB.

Results: The prevalence of normal-weight children without central OB was $64.3 \%$ (796), normal weight with central OB 5\% (66), OW/OB without central OB 11\% (137), and OW/OB with central OB $21 \%$ (265). Normal weight with central OB had significantly higher triglycerides than normal-weight children without central OB (86 vs $70 \mathrm{mg} / \mathrm{dL}$, respectively) and OW/OB children without central OB (81 vs 77 mg/dL). Multiple linear regression analyses showed that age, systolic $B P, H D L-C$, triglycerides, and maternal WC were significantly associated with children's WC; $R^{2}=0.50$ as well as children's $\mathrm{BMI} ; \mathrm{R}^{2}=0.37$.

Conclusion: This study found that children with central OB might be at future higher cardiometabolic risk than those without central OB independently of the presence of OW/OB. However, future longitudinal studies should be performed to confirm these findings.
\end{abstract} Key Words

\section{Introduction}

The current definition of overweight/obesity (OW/OB) using BMI has been questioned by current studies in adults, suggesting that BMI might not be the best indicator of cardiometabolic risk(1). The present definition of pediatrics
OW/OB is based on BMI and might omit children with cardiometabolic complications but who have a normal weight (2). Furthermore, three classifications based on growth charts developed by the Center for Disease Control https://ec.bioscientifica.com

https://doi.org/10.1530/EC-21-0139 (c) 2021 The authors Published by Bioscientifica Ltd

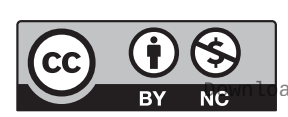

This work is licensed under a Creative Commons Attribution-NonCommercial 4.0 International License. ded from Bioscientifica.com at 04/26/2023 01:14:30PM 
(CDC), the World Health Organization (WHO), or the International Working Group on Obesity (IOTF) are used internationally. However, according to each definition, OW/OB's prevalence varies, being higher with the WHO definition, intermediate with the CDC, and lower with the IOTF (3). Therefore, there is still no international standard definition for childhood OW/OB. Besides, BMI has limited specificity for determining the degree of adiposity as it cannot identify ectopic fat deposits in the liver and the visceral compartments (4).

In the 1980s, Ruderman et al. studied a group of adults who had normal weight but who were metabolically unhealthy as they presented lower insulin sensitivity, higher triglycerides, and cardiovascular disease (5). Normal-weight adults with central OB, according to waist circumference (WC) cutoff, had the highest mortality risk compared with normal-weight subjects without central OB (6). Location is key when it comes to body fat distribution and is the main contributor to cardiometabolic risk (7). Our group found that WC in children was significantly associated with greater cardiometabolic risk (8). Accordingly, the Bogalusa Heart Study found that central OB was associated with an elevation of triglycerides, decreased HDL-C, and increased blood pressure (BP) (9), all components of cardiometabolic complications. A recent multicenter study from four areas of Argentina performed by our group in more than 1200 schoolchildren showed that OW/OB was associated with poorer dietary intake compared with normal weight (10). However, there is limited information about the distribution of cardiometabolic markers in normal weight and OW/OB Argentinean schoolchildren with and without central OB. The objective of the study was to describe cardiometabolic markers in four groups of children according to BMI/WC categories: (i) normal weight with central OB, (ii) normal weight without central $\mathrm{OB}$, (iii) $\mathrm{OW} / \mathrm{OB}$ with central $\mathrm{OB}$, and (iv) $\mathrm{OW} / \mathrm{OB}$ without central $\mathrm{OB}$ in a sample of schoolchildren living in Lavallol, Buenos Aires suburbs, Argentina.

\section{Methods}

This cross-sectional study was performed in Buenos Aires suburbs, Argentina, between November 2013 and 2015. The study was approved by the Human Rights Committee of the University of Buenos Aires. Each parent and child gave written informed consent after an explanation of the study and before its initiation. The study was conducted in accordance with the Declaration of Helsinki.
For the selection of the sample of children, a twostage cluster sampling was applied. The sample framework was the schools listed in each area from Lavallol, Buenos Aires suburbs. We considered the number of students for each school. In the first stage, the schools were selected using Sampford proportional to size sampling method, which was programmed in R. The number of schools selected was determined previously so that the number of students included in them will ensure an error of approximately $5 \%$ in each area with a 95\% CI, considering the correction factor for the finite population. Within the schools, the students were randomly selected. Given the fact that in a previous study, the prevalence of $\mathrm{OW} / \mathrm{OB}$ was approximately 33\% among children (11), the sample size was estimated to achieve an error lower than 0.05 . We examined approximately 1300 children, which means that the global sample error was less than 0.026. The sample is robust enough to represent the town of Lavallol, located in the western Buenos Aires suburbs.

Exclusion criteria were as follows: missing BMI information; not having fasted for at least $10 \mathrm{~h}$; children with known diabetes or other chronic disease and using medication that would affect BP or glucose or lipid metabolism was excluded. The overall response rate was $83.5 \%$ of students. There was no significant difference in the mean age $(P=0.81)$, BMI $(P=0.16)$, gender $(P=0.11)$, or socioeconomic class among all the school children and those who were included in the study.

Sociodemographic characteristics recorded included the level of education and the presence or absence of a refrigerator or a dirt floor in the house. These two indicators are used to identify families of very low socioeconomic status by the National Statistics and Censuses Institute of Argentina (12).

Height, weight, and WC were measured with participants wearing light clothing and no shoes. BMI was calculated as weight (in kilograms) divided by height (in meters) squared. BMI z-scores (BMI-z) were also determined (13). Children were classified as normal weight (5th to $<85$ th percentile), overweight (OW) (85th to $<95$ th percentile), or OB ( $\geq 95$ th percentile) according to the US Centers for Disease Control and Prevention (CDC) norms (13). The WC measurement was performed at the level of the umbilicus and was recorded at $0.1 \mathrm{~cm}$ (14). A flexible non-elastic tape measure was used with the child standing without clothing covering the waist area. Central OB was defined for children as waist circumference $\geq 90$ th percentile for age and gender based on 3000 normal Argentinean children (11). Children were divided into four groups: (i) normal weight with central OB; (ii) normal weight without central OB;

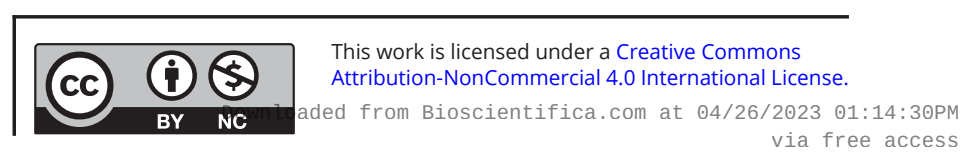


(iii) $\mathrm{OW} / \mathrm{OB}$ with central $\mathrm{OB}$ and (iv) $\mathrm{OW} / \mathrm{OB}$ without central OB. BP was measured by certified medical professionals in a standardized manner (15).

Plasma glucose was assessed by the glucose oxidase technique, and serum lipids were measured with a Modular P analyzer (Hitachi High Technologies Corp.). Serum insulin levels were determined by RIA (Diagnostic Products, Los Angeles, CA), and insulin did not cross-react with proinsulin or C-peptide (percentage coefficient of variance, $5.2-6.8 \%)$.

\section{Data analysis}

When comparing two groups with normally distributed data, a Student's $t$-test was performed. When comparing more than two groups and with data that were normally distributed, a one-way ANOVA was used (Student-NewmanKeuls post hoc test). When the homogeneity of the variances could not be proven, we used the non-parametric BrownForsythe test, with T3 Dunnett post hoc test. Variables with a skewed distribution were logarithmically transformed for analysis. After log transformation, the data were tested again to confirm the findings. Bonferroni's adjustment was carried out when many comparisons were performed.

The primary focus of the study was to determine the association between central $\mathrm{OB}$ and cardiometabolic risk in both normal weight and OW/OB Argentinean schoolchildren.

We performed multiple linear regression analyses using WC or BMI as dependent variables and age, gender, BPs, lipid levels, insulin levels, and maternal BMI and WC as independent variables in order to determine the association of each anthropometric variable and cardiometabolic risk factors. The data are expressed as means \pm S.D. or percentages. $P$ values $<0.05$ were considered significant. Analyses were performed using the SPSS statistical software package SPSS version $22.0^{\circledR}$.

\section{Results}

A cross-sectional study of 1264 Argentinean schoolchildren (624 females), aged $9.5 \pm 2.2$ years was performed between November 2013 and 2015. Socioeconomic level: 18.1\% of the fathers and $21.6 \%$ of the mothers had an elementary school education or less. None of the families had a dirt floor and only $2.9 \%$ did not have a refrigerator.

Clinical and metabolic characteristics of the sample according to gender are described in Table 1 . There were no significant differences in mean values of weight, height, BMI, z-BMI, systolic and diastolic BP, hemoglobin, or cholesterol between girls and boys. However, girls were older and had significantly higher triglycerides, insulin, and triglycerides/HDL-C levels than boys. In contrast, glucose levels were higher in boys than in girls.

The prevalence of OW/OB was 32\% (405) and central OB was $24.5 \%$ (310). Children were divided in four groups (i) normal weight with central OB; (ii) normal weight without central OB; (iii) OW/OB with central OB and (iv) OW/OB without central OB) (Table 2). The prevalence of

Table 1 Clinical and metabolic characteristics according to gender. Data are presented as mean \pm S.D. Z-score is a quantitative measure of the deviation of a specific variable taken from the mean of that population. CDC z-BMI takes into account age and sex.

\begin{tabular}{l}
\hline \\
\hline Age (years) \\
Height (m) \\
z-Height \\
WC (cm) \\
Systolic BP (mmHg) \\
Diastolic BP (mmHg) \\
BMI \\
z-BMI \\
Hb (g/dL) \\
Total cholesterol (mg/dL) \\
TG (mg/dL) \\
HDL-C (mg/dL) \\
Glucose (mg/dL) \\
Insulin (IU/dL) \\
TG/HDL-C \\
Non-HDL-C (mg/dL)
\end{tabular}

\begin{tabular}{c} 
Male $(n=640 ; 50.6 \%)$ \\
\hline $9.38 \pm 2.13$ \\
$1.34 \pm 0.13$ \\
$-0.25 \pm 0.95$ \\
$64.82 \pm 11.05$ \\
$94.25 \pm 13.58$ \\
$57.47 \pm 9.76$ \\
$18.67 \pm 3.75$ \\
$0.6 \pm 1$ \\
$13.23 \pm 0.84$ \\
$151.11 \pm 27.56$ \\
$73.48 \pm 36.74$ \\
$49.86 \pm 11.88$ \\
$79.18 \pm 8.84$ \\
$5.17 \pm 4.21$ \\
$1.64 \pm 1.31$ \\
$101.09 \pm 25.25$
\end{tabular}

\begin{tabular}{c} 
Female $(n=624 ; 49.4 \%)$ \\
\hline $9.67 \pm 2.21^{\mathrm{a}}$ \\
$1.35 \pm 0.14$ \\
$-0.27 \pm 0.93$ \\
$65.29 \pm 10.78$ \\
$93.4 \pm 14.51$ \\
$57.26 \pm 9.93$ \\
$18.77 \pm 3.64$ \\
$0.5 \pm 0.98$ \\
$13.22 \pm 0.9$ \\
$153.99 \pm 27.19$ \\
$81.45 \pm 38.46^{\mathrm{b}}$ \\
$48.95 \pm 11.67$ \\
$77.57 \pm 8.49^{\mathrm{b}}$ \\
$6.67 \pm 6.4^{\mathrm{b}}$ \\
$1.82 \pm 1.12^{\mathrm{b}}$ \\
$105 \pm 25.44$
\end{tabular}

Total $(n=1264)$
$9.52 \pm 2.17$
$1.34 \pm 0.13$
$-0.26 \pm 0.94$
$65.05 \pm 10.92$
$93.83 \pm 14.05$
$57.36 \pm 9.84$
$18.72 \pm 3.7$
$0.55 \pm 0.99$
$13.23 \pm 0.87$
$152.53 \pm 27.4$
$77.41 \pm 37.79$
$49.41 \pm 11.78$
$78.38 \pm 8.71$
$5.89 \pm 5.43$
$1.73 \pm 1.22$
$103.02 \pm 25.41$

${ }^{\mathrm{a}} \mathrm{P}<0.05$ and ${ }^{\mathrm{b}} \mathrm{P}<0.01$.

$\mathrm{BP}$, blood pressure; TG, triglycerides; z-BMI, BMI z-score.

https://ec.bioscientifica.com

https://doi.org/10.1530/EC-21-0139 (c) 2021 The authors Published by Bioscientifica Ltd

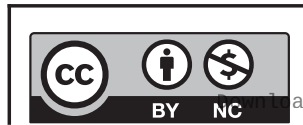

This work is licensed under a Creative Commons Attribution-NonCommercial 4.0 International License. ded from Bioscientifica.com at 04/26/2023 01:14:30PM 
Table 2 Clinical characteristics by central OB in normal weight and OW/OB children. Data are presented as mean \pm S.D. Z-score is a quantitative measure of the deviation of a specific variable taken from the mean of that population. CDC z-BMI takes into account age and sex.

\begin{tabular}{l}
\hline \\
\hline Age (years) $(a, b)$ \\
Height $(m)(b, c, e)$ \\
BMI $(g)$ \\
WC $(c m)(g)$ \\
z-BMI $(g)$ \\
z-Height $(a, b, e)$ \\
Systolic BP (mmHg) $(b, e, f)$ \\
Diastolic BP (mmHg) $(a, b, e)$ \\
Hb (g/dL)(b,c) \\
HDL-C (mg/dL) (b,e,f) \\
TG (mg/dL) (b,c, d,e,f) \\
TG/HDL-C (b,c,e,f) \\
Non-HDL-C (b,e) \\
Total cholesterol (mg/dL) \\
Glucose (mg/dL) \\
Insulin IU(b,e) \\
Maternal BMI $(a, c, e, f)$ \\
Maternal WC (cm) $(a, e)$
\end{tabular}

\begin{tabular}{c}
$\begin{array}{c}\text { Normal weight without } \\
\text { central OB }(n=796 ; 63 \%)\end{array}$ \\
\hline $9.53 \pm 2.18$ \\
$133.11 \pm 13.1$ \\
$16.79 \pm 1.7$ \\
$59.84 \pm 6.22$ \\
$-0.01 \pm 0.71$ \\
$-0.46 \pm 0.9$ \\
$91.67 \pm 12.98$ \\
$55.85 \pm 9.3$ \\
$13.21 \pm 0.82$ \\
$50.97 \pm 11.69$ \\
$70.23 \pm 29.92$ \\
$1.48 \pm 0.81$ \\
$100.16 \pm 25.71$ \\
$151.25 \pm 28.11$ \\
$77.9 \pm 8.83$ \\
$5 \pm 5.23$ \\
$25.1 \pm 5.83$ \\
$86.77 \pm 12.05$
\end{tabular}

\begin{tabular}{|c|}
\hline $\begin{array}{l}\text { Normal weight with } \\
\text { central OB }(n=66 ; 5 \%)\end{array}$ \\
\hline $9.86 \pm 2.74$ \\
\hline $137.84 \pm 15.49$ \\
\hline $18.72 \pm 2$ \\
\hline $72.58 \pm 8.22$ \\
\hline $0.65 \pm 0.36$ \\
\hline$-0.08 \pm 0.86$ \\
\hline $93.93 \pm 13.09$ \\
\hline $57.48 \pm 9.87$ \\
\hline $13.69 \pm 1.61$ \\
\hline $49.33 \pm 13.49$ \\
\hline $85.64 \pm 27.35$ \\
\hline $1.88 \pm 0.89$ \\
\hline $105.81 \pm 22.13$ \\
\hline $156.09 \pm 24.18$ \\
\hline $79.41 \pm 10.47$ \\
\hline $7.14 \pm 5.56$ \\
\hline $24.38 \pm 5.8$ \\
\hline $91.63 \pm 11.51$ \\
\hline
\end{tabular}

\begin{tabular}{c}
$\begin{array}{c}\text { OW/OB without central } \\
\text { OB }(n=137 ; 11 \%)\end{array}$ \\
\hline $8.94 \pm 1.96$ \\
$131.73 \pm 12.26$ \\
$20.14 \pm 1.92$ \\
$64.84 \pm 7.2$ \\
$1.38 \pm 0.32$ \\
$-0.16 \pm 0.91$ \\
$93.74 \pm 14.11$ \\
$58.26 \pm 9.35$ \\
$13.02 \pm 0.69$ \\
$49.9 \pm 10.38$ \\
$70.47 \pm 26.86$ \\
$1.51 \pm 0.74$ \\
$103.66 \pm 20.71$ \\
$153.56 \pm 22.2$ \\
$79.39 \pm 8.44$ \\
$6.13 \pm 4.31$ \\
$28.02 \pm 7.44$ \\
$92.48 \pm 13.82$
\end{tabular}

\begin{tabular}{|c|}
\hline $\begin{array}{c}\text { OW/OB with central } \\
\text { OB }(n=265 ; 21 \%)\end{array}$ \\
\hline $9.73 \pm 2.13$ \\
\hline $138.97 \pm 12.08$ \\
\hline $23.84 \pm 3.78$ \\
\hline $79.52 \pm 10.13$ \\
\hline $1.81 \pm 0.4$ \\
\hline $0.28 \pm 0.88$ \\
\hline $100.51 \pm 15.39$ \\
\hline $61.42 \pm 10.45$ \\
\hline $13.23 \pm 0.87$ \\
\hline $44.03 \pm 10.84$ \\
\hline $101.03 \pm 52.57$ \\
\hline $2.57 \pm 1.93$ \\
\hline $110.7 \pm 25.58$ \\
\hline $154.71 \pm 27.81$ \\
\hline $79.18 \pm 7.9$ \\
\hline $8.6 \pm 5.69$ \\
\hline $28.97 \pm 7.72$ \\
\hline $96.72 \pm 13.62$ \\
\hline
\end{tabular}

Significant differences ( $P$ values $<0.05$ ) were found between (a) normal weight without central OB vs OW/OB without central OB; (b) OW/OB without central $\mathrm{OB}$ vs $\mathrm{OW} / \mathrm{OB}$ with central $\mathrm{OB}$; (c) normal weight with central $\mathrm{OB}$ vs $\mathrm{OW} / \mathrm{OB}$ without central $\mathrm{OB}$; (d) normal weight without central $\mathrm{OB}$ vs normal weight with central OB; (e) normal weight without central OB vs OW/OB with central OB; (f) normal weight with central OB vs OW/OB with central OB; (g) all categories are significantly dif ferent.

$\mathrm{BP}$, blood pressure; OB, obesity; OW, overweight; TG, triglycerides; z-BMI, BMI z-score.

normal weight children without central OB was $64.3 \%$ (796), normal weight with central 5\% (66), OW/OB without central $\mathrm{OB} 11 \%(137)$, and $\mathrm{OW} / \mathrm{OB}$ with central OB $21 \%$ (265). We found that normal-weight children with central OB had significantly higher triglycerides than normal weight and OW/OB children without central $\mathrm{OB}$. It is interesting to note that normal-weight children with central OB had lower BMI but higher WC than OW/OB children without central OB. Finally, OW/OB children with central OB had significantly higher systolic and diastolic $\mathrm{BP}$, triglycerides, triglycerides/HDL-C, non-HDL-C, insulin levels, and lower HDL-C than OW/OB children without central OB.

\section{Multivariate associations}

Multiple linear regression analyses showed that age, systolic BP, HDL-C, triglycerides, and maternal WC were

Table 3 Multiple linear regression analyses.

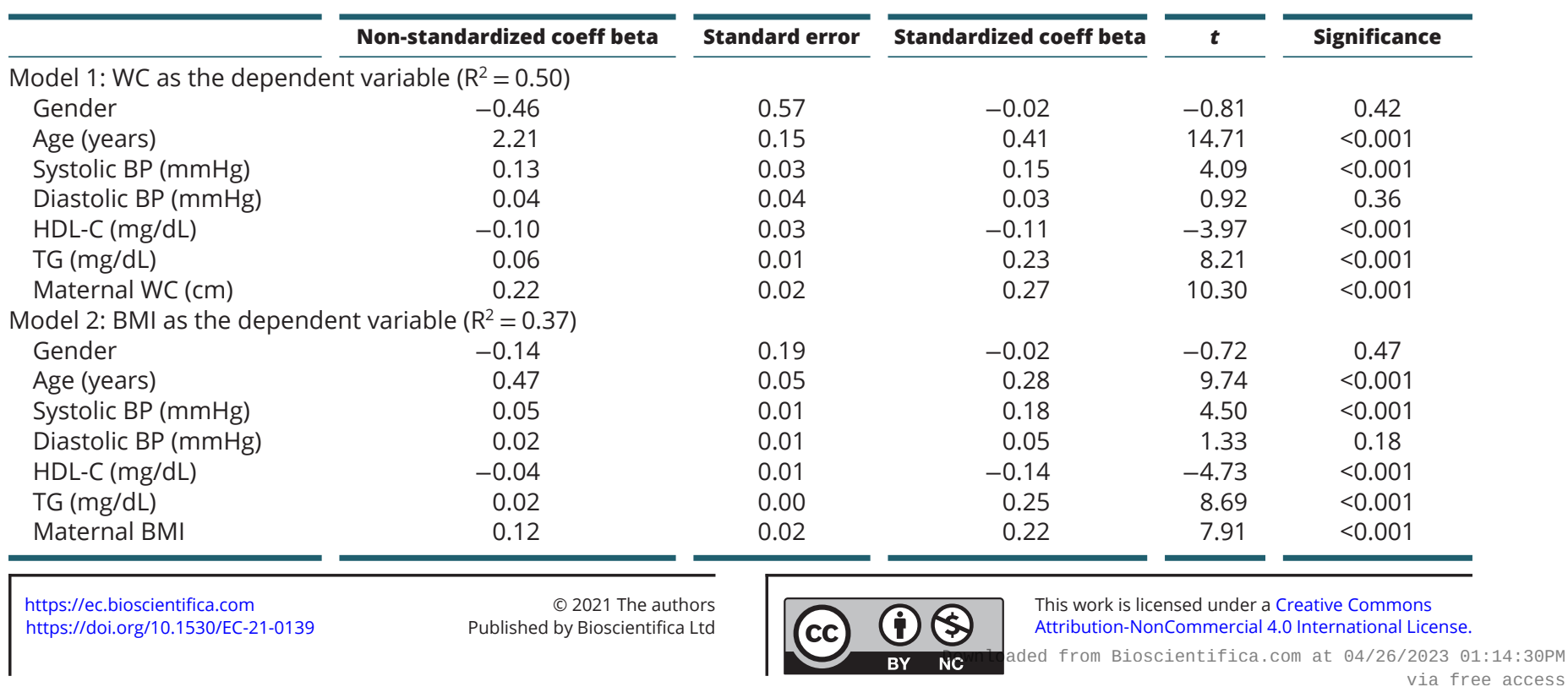


significantly associated with children's WC; adjusted for gender and diastolic BP, $\mathrm{R}^{2}=0.50$ (Table 3, model 1). In addition, age, systolic and diastolic BP, triglycerides, and maternal BMI were associated with children's BMI; adjusted for gender and diastolic $B P, R^{2}=0.37$ (Table 3, model 2). Adjusted-R-squared measures the strength of the relationship between our models and the dependent variable. Adjusted- $\mathrm{R}^{2}$ value was higher in the multivariate model using WC as the dependent variable (model 1), suggesting a slightly better fitting when compared with model 2 (using BMI as the dependent variable).

\section{Discussion}

The present study found that normal-weight schoolchildren with central OB had higher triglycerides than normal-weight children without central OB and OW/ OB children without central OB. Besides, OW/OB children with central $\mathrm{OB}$ had higher BP, lipids, and insulin levels than OW/OB children without central OB. These suggest that central $\mathrm{OB}$ was associated with higher cardiometabolic markers, independently of the presence of OW/OB. There is strong evidence demonstrating that higher WC is associated with cardiometabolic complications in adults, even in individuals with BMI within the normal range (16). A 30-year Australian report (1985-2015) found that the prevalence of central OB doubled the prevalence of OB in primary school children, while the $\mathrm{OB}$ rates remained stable. The authors suggested that BMI is a surrogate measure for total adiposity and does not describe body fat distribution, which may be strongly associated with cardiometabolic complications than total adiposity (17). As far as we know, no large studies have been conducted in Argentinean schoolchildren about the distribution of cardiometabolic markers in (i) normal weight with central $\mathrm{OB}$; (ii) normal weight without central OB; (iii) $\mathrm{OW} / \mathrm{OB}$ with central $\mathrm{OB}$ and (iv) $\mathrm{OW} / \mathrm{OB}$ without central $\mathrm{OB}$. We concluded that children with central OB might be at future higher cardiometabolic risk than those without central $\mathrm{OB}$ independently of the presence of OW/OB. However, future longitudinal studies should be done to confirm these findings.

$\mathrm{OB}$ is strongly correlated with a significant number of cardiometabolic disorders (18). A follow-up study performed in 276,835 Danish schoolchildren found that the risk of any coronary heart disease among adults was positively associated with BMI at 7-13 years of age for boys and 10-13 years of age for girls (19). Since the publication of the BMI percentiles by the Centers for Disease Control in 2000 (2), pediatricians have been using BMI for OW/OB screening. However, different studies showed that central OB was closely associated with cardiometabolic risk (5, 8, $9,16)$. Consistently, the present study showed that WC was a better marker of cardiometabolic complications than BMI after adjustments for confounding variables. It has been shown that measurements of central OB, principally WC, were more closely related to metabolic risk factors than the index of general adiposity (20). Park et al. found that WC was a better predictor of coronary artery calcification than BMI (21). Furthermore, a study performed in 160 OW/OB children showed that those with WC above the 90th percentile had increased left ventricular mass index and concentric hypertrophy (22). They suggested that OB children with higher WC should be closely followed up to avoid future cardiovascular diseases (23). Consistently, our group previously found that the left atrial area was significantly associated with WC in children, suggesting that WC was a risk factor for left area enlargement (22). Left area enlargement was associated with an increased risk of stroke and death in adults (24).

The KNHANES (2013-2015) studied more than 10,000 normal-weight Koreans and showed that central OB was associated with impaired fasting glucose and diabetes in men and hypertriglyceridemia and low HDL-C in women (2). They concluded that cardiometabolic complications were associated with central OB in Korean adults with normal BMI, suggesting that control of central OB in adults with normal weight was highly recommended (25). The present study showed that both normal weight and OW/OB schoolchildren with central OB had higher cardiometabolic markers compared with those without central OB. Consistently, Wildman et al. showed that the major risk factors for cardiometabolic abnormalities among individuals with normal weight were older age, lower physical activity, and larger WC (16). Furthermore, Matsuzawa (26) reported evidence that Japanese Sumo wrestlers were metabolically healthy probably due to normal amounts of central adiposity despite consuming 5000-7000 kcal/day. However, when they took a break from wrestling, cardiometabolic complications emerged, suggesting that physically active individuals might also be protected. Dvorak et al. (27) showed that total daily energy expenditure due to physical activity might explain differences in body fat distribution in metabolically unhealthy normal-weight individuals. The mechanisms related to the larger WC in normal and OW/OB subjects are unclear but might be associated with high secretory adipose tissue or increased responsiveness to the effects of adipokines (16). A review proposed that

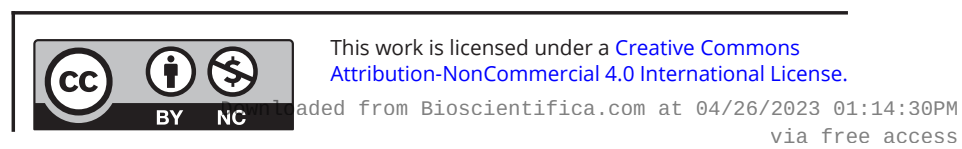


excess caloric intake leads to an increase in body fat. The expansion ability of the s.c. fat tissue determines the lipid partition profile (28). Those with a greater ability to expand the s.c. depot will have less intra-abdominal and hepatic/muscle fat deposition and, therefore, will be more sensitive to insulin (28). Those with an inability to expand their s.c. fat will have an unfavorable lipid partition profile with increased intra-abdominal lipid deposition and, therefore, higher waist circumference, liver/muscle fat deposition, and insulin resistance (28). There are no sufficient data about the influence of genetics and epigenetics among healthy and unhealthy phenotypes. However, it is probable that both genetic and epigenetic variation might be associated with these different phenotypes (29). Moreover, limited genomewide integrative analyses have been performed yet (29). In that case, healthier lifestyle behaviors should be promoted in children with central OB in order to prevent future cardiometabolic complications.

\section{Limitations}

Only WC was used to define central OB; this may not be an accurate evaluation of visceral fat. If abdominal MRI or dual-energy x-ray absorptiometry is used to measure visceral fat, more accurate central $\mathrm{OB}$ results can be obtained. The influence of fat distribution may be more clearly determined. Moreover, because this study was cross-sectional, we could not investigate the chronological relationship between variables and central OB so we could not identify any causal relationships. Finally, this study lacked information regarding physical activity, dietary habits, and family history of cardiovascular disease.

The strength of our study included the large school-age population-based sample of apparently normal children from Lavallol exploring cardiometabolic characteristics in normal weight and $\mathrm{OW} / \mathrm{OB}$ children with and without central $\mathrm{OB}$. The high response rate of the children, the collection of fasting blood samples, and the use of multiple regression models allowed investigators to account for the complex interrelationships between these physiologic traits and potential confounders such as gender, age, children's BPs, lipid, glucose, and insulin as well as maternal WC and BMI.

There is no absolute standard for a 'good' value of adjusted $\mathrm{R}^{2}$. It depends on the situation, in particular, on the 'signal-to-noise ratio' in the dependent variable. These factors limit interpretations of the differences observed between our two multivariate models.
However, wefound that children with centralOB had higher values of cardiometabolic markers than those without central OB.

\section{Conclusion}

This study found that children with central OB might be at future higher cardiometabolic risk than those without central $\mathrm{OB}$ independently of the presence of OW/OB. However, future longitudinal studies should be performed to confirm these findings.

\section{Declaration of interest}

The authors declare that there is no conflict of interest that could be perceived as prejudicing the impartiality of the research reported.

\section{Funding}

This study did not receive any specific grant from any funding agency in the public, commercial or not-for-profit sector.

\section{References}

1 Oliveros E, Somers VK, Sochor O, Goel K \& Lopez-Jimenez F. The concept of normal weight obesity. Progress in Cardiovascular Diseases 201456 426-433. (https://doi.org/10.1016/j.pcad.2013.10.003)

2 Ogden CL, Kuczmarski RJ, Flegal KM, Mei Z, Guo S, Wei R, GrummerStrawn LM, Curtin LR, Roche AF \& Johnson CL. Centers for Disease Control and Prevention 2000 growth charts for the United States: improvements to the 1977 National Center for Health Statistics version. Pediatrics 2002109 45-60. (https://doi.org/10.1542/ peds.109.1.45)

3 Chung ST, Onuzuruike AU \& Magge SN. Cardiometabolic risk in obese children. Annals of the New York Academy of Sciences 20181411 166-183. (https://doi.org/10.1111/nyas.13602)

4 Staiano AE, Broyles ST, Gupta AK \& Katzmarzyk PT. Ethnic and sex differences in visceral, subcutaneous, and total body fat in children and adolescents. Obesity 201321 1251-1255. (https://doi.org/10.1002/ oby.20210)

5 Ruderman NB, Schneider SH \& Berchtold P. The 'metabolically-obese,' normal-weight individual. American Journal of Clinical Nutrition 1981 34 1617-1621. (https://doi.org/10.1093/ajcn/34.8.1617)

6 Coutinho T, Goel K, Correa de Sa D, Kragelund C, Kanaya AM, Zeller M, Park JS, Kober L, Torp-Pedersen C, Cottin Y, et al. Central obesity and survival in subjects with coronary artery disease: a systematic review of the literature and collaborative analysis with individual subject data. Journal of the American College of Cardiology 201157 1877-1886. (https://doi.org/10.1016/j.jacc.2010.11.058)

7 Rubin R. What's the best way to treat normal-weight people with metabolic abnormalities? JAMA 2018320 223-225. (https://doi. org/10.1001/jama.2018.8188)

8 Hirschler V, Aranda C, Calcagno Mde L, Maccalini G \& Jadzinsky M. Can waist circumference identify children with the metabolic syndrome? Archives of Pediatrics and Adolescent Medicine 2005159 740-744. (https://doi.org/10.1001/archpedi.159.8.740)

9 Freedman DS, Serdula MK, Sat Srinivasan SR \& Berenson GS. Relation of circumferences and skinfold thicknesses to lipid and insulin 
concentrations in children and adolescents: the Bogalusa Heart Study. American Journal of Clinical Nutrition 199969 308-317. (https://doi. org/10.1093/ajcn/69.2.308)

10 Hirschler V, Lapertosa S, Scaiola R, Garcia C, Maldonado N, Guntsche Z, Miorin C, Obeziuk A, Molinari C, Gonzalez C, et al. Adiposity, lifestyle behaviors, and cardiometabolic markers in Argentinean schoolchildren. Clinica Chimica Acta 2020507 280-285. (https://doi.org/10.1016/j.cca.2020.05.008)

11 Hirschler V, Oestreicher K, Maccallini G \& Aranda C. Relationship between obesity and metabolic syndrome among Argentinean elementary schoolchildren. Clinical Biochemistry 201043 435-441. (https://doi.org/10.1016/j.clinbiochem.2009.11.003)

12 INDEC. Instituto Nacional de Estadística y Censos de la Republica Argentina (accessed February 2019), 2010. (available at: http://www. censo2010.indec.gov.ar/).

13 Kuczmarski RJ, Ogden CL, Guo SS, Grummer-Strawn LM, Flegal KM, Mei Z, Wei R, Curtin LR, Roche AF \& Johnson CL. 2000 CDC growth charts for the United States: methods and development. Vital and Health Statistics: Series 112002246 1-190. (available at: https://www. cdc.gov/growthcharts/index.htm)

14 McCarthy HD, Ellis SM \& Cole TJ. Central overweight and obesity in British youth aged 11-16 years: cross sectional surveys of waist circumference. BMJ 2003326 624. (https://doi.org/10.1136/ bmj.326.7390.624)

15 Flynn JT, Kaelber DC, Baker-Smith CM, Blowey D, Carroll AE, Daniels SR, de Ferranti SD, Dionne JM, Falkner B, Flinn SK, et al. Clinical practice guideline for screening and management of high blood pressure in children and adolescents. Pediatrics 2017140 e20171904. (https://doi.org/10.1542/peds.2017-1904)

16 Wildman RP, Muntner P, Reynolds K, McGinn AP, Rajpathak S, WylieRosett J \& Sowers MR. The obese without cardiometabolic risk factor clustering and the normal weight with cardiometabolic risk factor clustering: prevalence and correlates of 2 phenotypes among the US population (NHANES 1999-2004). Archives of Internal Medicine 2008 168 1617-1624. (https://doi.org/10.1001/archinte.168.15.1617)

17 Hardy LL, Mihrshahi S, Gale J, Drayton BA, Bauman A \& Mitchell J. 30-year trends in overweight, obesity and waist-to-height ratio by socioeconomic status in Australian children, 1985 to 2015. International Journal of Obesity 201741 76-82. (https://doi.org/10.1038/ ijo.2016.204)

18 Global Burden of Metabolic Risk Factors for Chronic Diseases Collaboration (BMI Mediated Effects), Lu Y, Hajifathalian K, Ezzati M, Woodward M, Rimm EB \& Danaei G. Metabolic mediators of the effects of body-mass index, overweight, and obesity on coronary heart disease and stroke: a pooled analysis of 97 prospective cohorts with 1.8 million participants. Lancet 2014383 970-983. (https://doi. org/10.1016/S0140-6736(13)61836-X)

19 Baker JL, Olsen LW \& Sørensen TI. Childhood body-mass index and the risk of coronary heart disease in adulthood. New England
Journal of Medicine 2007357 2329-2337. (https://doi.org/10.1056/ NEJMoa072515)

20 Czernichow S, Kengne AP, Stamatakis E, Hamer M \& Batty GD. Body mass index, waist circumference and waist-hip ratio: which is the better discriminator of cardiovascular disease mortality risk? Evidence from an individual-participant meta-analysis of 82864 participants from nine cohort studies. Obesity Reviews 201112 680-687. (https:// doi.org/10.1111/j.1467-789X.2011.00879.x)

21 Park J, Lee ES, Lee DY, Kim J, Park SE, Park CY, Lee WY, Oh KW, Park SW \& Rhee EJ. Waist circumference as a marker of obesity is more predictive of coronary artery calcification than body mass index in apparently healthy Korean adults: the Kangbuk Samsung Health Study. Endocrinology and Metabolism 201631 559-566. (https://doi. org/10.3803/EnM.2016.31.4.559)

22 Hirschler V, Acebo HL, Fernandez GB, de Lujan Calcagno M, Gonzalez C \& Jadzinsky M. Influence of obesity and insulin-resistance on left atrial size in children. Pediatric Diabetes 20067 39-44. (https:// doi.org/10.1111/j.1399-543X.2006.00139.x)

23 Trandafir LM, Russu G, Moscalu M, Miron I, Lupu VV, Leon Constantin MM, Cojocaru E, Lupu A \& Frasinariu OE. Waist circumference a clinical criterion for prediction of cardio-vascular complications in children and adolescences with overweight and obesity. Medicine 202099 e20923. (https://doi.org/10.1097/ MD.0000000000020923)

24 Benjamin EJ, D’Agostino RB, Belanger AJ, Wolf PA \& Levy D. Left atrial size and the risk of stroke and death: the Framingham Heart Study. Circulation 199592 835-841.

25 Kim HY, Kim JK, Shin GG, Han JA \& Kim JW. Association between abdominal obesity and cardiovascular risk factors in adults with normal body mass index: based on the Sixth Korea National Health and Nutrition Examination Survey. Journal of Obesity and Metabolic Syndrome 201928 262-270. (https://doi.org/10.7570/ jomes.2019.28.4.262)

26 Matsuzawa Y. Pathophysiology and molecular mechanisms of visceral fat syndrome: the Japanese experience. Diabetes/Metabolism Reviews 199713 3-13. (https://doi.org/10.1002/(sici) 10990895(199703)13:1<3::aid-dmr178>3.0.co;2-n)

27 Dvorak RV, DeNino WF, Ades PA \& Poehlman ET. Phenotypic characteristics associated with insulin resistance in metabolically obese but normal-weight young women. Diabetes 199948 2210-2214. (https://doi.org/10.2337/diabetes.48.11.2210)

28 Ighbariya A \& Weiss R. Insulin resistance, prediabetes, metabolic syndrome: what should every pediatrician know? Journal of Clinical Research in Pediatric Endocrinology 20179 (Supplement 2) 49-57. (https://doi.org/10.4274/jcrpe.2017.S005)

29 Diels S, Vanden Berghe W \& Van Hul W. Insights into the multifactorial causation of obesity by integrated genetic and epigenetic analysis. Obesity Reviews 202021 e13019. (https://doi. org/10.1111/obr.13019)

Received in final form 17 June 2021

Accepted 14 July 2021

Accepted Manuscript published online 14 July 2021 https://ec.bioscientifica.com https://doi.org/10.1530/EC-21-0139 (c) 2021 The authors Published by Bioscientifica Ltd

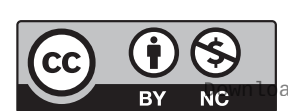

This work is licensed under a Creative Commons Attribution-NonCommercial 4.0 International License. ated from Bioscientifica com at 04/26/2023 01:14:30PM 